\title{
A Transgenic Marker for Newly Born Granule Cells in Dentate Gyrus
}

\author{
Linda S. Overstreet, ${ }^{1}$ Shane T. Hentges, ${ }^{1}$ Viviana F. Bumaschny, ${ }^{4}$ Flavio S. J. de Souza, ${ }^{4}$ James L. Smart, ${ }^{1}$ \\ Andrea M. Santangelo, ${ }^{4}$ Malcolm J. Low, ${ }^{1,2,3}$ Gary L. Westbrook, ${ }^{1}$ and Marcelo Rubinstein ${ }^{3,4,5}$ \\ ${ }^{1}$ Vollum Institute, ${ }^{2}$ Department of Behavioral Neuroscience, and ${ }^{3}$ The Center for Study of Weight Regulation and Associated Disorders, Oregon Health and \\ Science University, Portland, Oregon 97239, ${ }^{4}$ Instituto de Investigaciones en Ingeniería Genética y Biología Molecular, Consejo Nacional de Investigaciones \\ Científicas y Técnicas, y Departamento de Fisiología, Biología Molecular y Celular, Facultad de Ciencias Exactas y Naturales, Universidad de Buenos Aires, \\ 1428 Buenos Aires, Argentina, and ${ }^{5}$ Centro de Estudios Científicos, Casilla 1469, Valdivia, Chile
}

Neurogenesis in the dentate gyrus continues into adulthood, yet little is known about the function of newly born neurons or how they integrate into an existing network of mature neurons. We made transgenic mice that selectively and transiently express enhanced green fluorescent protein (EGFP) in newly born granule cells of the dentate gyrus under the transcriptional control of proopiomelanocortin (POMC) genomic sequences. Analysis of transgenic pedigrees with truncation or deletion mutations indicated that EGFP expression in the dentate gyrus required cryptic POMC promoter regions dispensable for arcuate hypothalamic or pituitary expression. Unlike arcuate neurons, dentate granule cells did not express the endogenous POMC gene. EGFP-positive neurons had immature properties, including short spineless dendrites and small action potentials. Colocalization with bromodeoxyuridine indicated that EGFP-labeled granule cells were $\sim 2$ weeks postmitotic. EGFP-labeled cells expressed markers for immature granule cells but not the glial marker GFAP. The number of EGFP-labeled neurons declined with age and increased with exercise, paralleling neurogenesis. Our results indicate that POMC-EGFP marks immature granule cells and that adult-generated granule cells integrate quite slowly into the hippocampal circuitry.

Key words: neurogenesis; neuronal progenitor; dentate granule cell; green fluorescent protein; transgenic mice; proopiomelanocortin; BrdU; PSA-nCAM

\section{Introduction}

In most brain regions, the proliferation and differentiation of neurons is restricted to early developmental periods. However, neurogenesis continues throughout adult life in the olfactory system, where neuronal precursors originate in the subventricular zone and migrate to the olfactory bulb via the rostral migratory stream (Lois and Alvarez-Buylla, 1994). In the dentate gyrus, granule cells are generated in the subgranular zone between the hilus and granule cell layer (Kaplan and Hinds, 1977; Kuhn et al., 1996). There is mounting evidence that neurogenesis serves an important function in the adult brain. For example, manipulations that increase neurogenesis in the dentate gyrus are correlated with enhanced memory function (van Praag et al., 1999a; Rochefort et al., 2002), whereas stress decreases cell proliferation and memory performance (McEwen, 1999). Adult neurogenesis

\footnotetext{
Received Nov. 23, 2003; revised Feb. 17, 2004; accepted Feb. 18, 2004.

This work was supported by Fogarty International Research Collaborative Award TW01233 (M.J.L., M.R.), Agencia Nacional de Promocion Cientifica y Tecnologica, the J. S. Guggenheim Foundation, the Howard Hughes Medical Institute (M.R.), and National Institutes of Health Grants NS26494 (G.L.W.) and DK55819 (M.J.L.). We thank AeSoon Bensen and Forrest Davis for technical assistance, as well as the Oregon Health and Science University Transgenic Core Laboratory for microinjection of most transgenic constructs.

Correspondence should be addressed to either of the following: Dr. Marcelo Rubinstein, Instituto de Investigaciones en Ingeniería Genética y Biología Molecular-Consejo Nacional de Investigaciones Científicas y Técnicas, Vuelta de Obligado 2490, 1428 Buenos Aires, Argentina, E-mail: mrubins@dna.uba.ar; or Dr. Linda Overstreet, Vollum Institute, Oregon Health and Science University, Portland, OR 97239, E-mail: overstre@ohsu.edu. DOI:10.1523/JNEUROSCI.5173-03.2004

Copyright $\odot 2004$ Society for Neuroscience $\quad$ 0270-6474/04/243251-09\$15.00/0
}

may also be involved in the pathogenesis of mood disorders (Santarelli et al., 2003). Furthermore, enhanced neurogenesis after ischemia and epilepsy suggests that newborn neurons could potentially contribute to functional recovery (Liu et al., 1998; Magavi et al., 2000). Together, these studies suggest that neurogenesis is a regulated process that can be modified to influence behavior.

Just as the developing brain undergoes critical periods characterized by significant activity-dependent modification (for review, see Zhang and Poo, 2001), immature granule cells in the adult dentate gyrus exhibit lower thresholds for activitydependent synaptic plasticity such as long-term potentiation (van Praag et al., 1999a; Wang et al., 2000; Snyder et al., 2001). Although immature neurons in adult tissue have distinct electrophysiological features (Wang et al., 2000; Carleton et al., 2003), at least some adult-generated granule cells eventually develop into mature neurons with properties similar to their predecessors (van Praag et al., 2002). However, a high proportion of newborn cells undergo cell death during the first several weeks after final cell division (Biebl et al., 2000; Dayer et al., 2003). Little is known about the molecular cues that determine the fate of adultgenerated neurons. The prolific neurogenesis in avian forebrain suggests that environmental factors can strongly influence proliferation and survival with some predetermined genetic constraints (for review, see Nottebohm, 2002).

Exploring the properties and integration of adult-generated 
neurons has been hindered by the inability to track newborn neurons at the level of single cells. Here we report a transgenic model in which newly born granule cells are selectively labeled with enhanced green fluorescent protein (EGFP) expressed under the transcriptional control of the mouse proopiomelanocortin (POMC) gene promoter. EGFP-positive cells have morphological and physiological characteristics consistent with immature granule cells. EGFP expression is transient, peaking at 2 weeks after mitosis and turning off by 1 month. POMC-EGFP transgenic mice allow visualization of adult-generated granule cells, thus providing an opportunity to study their development and fate within a restricted temporal window. In addition, our results suggest that full incorporation of newly born granule cells into the hippocampal circuitry occurs relatively slowly.

\section{Materials and Methods}

Mice. Transgene $-13 /+8 P O M C-E G F P$ was microinjected into one of the pronuclei of C57BL/6J mouse zygotes as described previously (Cowley et al., 2001). The transgene contains the entire transcriptional unit of the mouse POMC gene together with $13 \mathrm{~kb}$ of $5^{\prime}$ flanking sequences and $2 \mathrm{~kb}$ of $3^{\prime}$ flanking sequences. EGFP (Clontech, Palo Alto, CA) coding sequences including a Kozac's site and a simian virus 40 polyadenylation site were inserted into the $5^{\prime}$ untranslated region of the second exon of the mouse POMC gene. Other POMC-EGFP transgenes were constructed from $-13 /+8 P O M C$-EGFP using standard subcloning techniques and were microinjected as described above. Electrophysiological studies were performed in heterozygous -13/+8POMC-EGFP transgenic mice maintained under a $\mathrm{C} 57 \mathrm{BL} / 6 \mathrm{~J}$ genetic background. All animal procedures were conducted in accordance with the Guide for the Care and Use of Laboratory Animals by the United States Public Health Service.

Mice were anesthetized with 2,2,2-tribromoethanol (Avertin; Aldrich, St. Louis, MO) and transcardially perfused with $4 \%$ paraformaldehyde in PBS. The brains were removed and postfixed for $16 \mathrm{hr}$ at $4^{\circ} \mathrm{C}$, sliced in 50 $\mu \mathrm{m}$ coronal sections, and immediately mounted on glass slides with Fluorsave (Calbiochem, La Jolla, CA). Postnatal d 8 (P8) mice were decapitated under $\mathrm{CO}_{2}$ anesthesia, and the brain was dissected out and immediately fixed in 4\% paraformaldehyde in PBS for $16 \mathrm{hr}$ at $4^{\circ} \mathrm{C}$. Brains were then transferred to a series of solutions containing PBS and increasing concentrations of sucrose (10, 20, and 30\%) every $24 \mathrm{hr}$. After cryoprotection, $25 \mu \mathrm{m}$ coronal brain sections were cut using a sliding microtome (SM2000R; Leica, Nussloch, Germany).

EGFP immunohistochemistry. Fixed sections were incubated in $1 \%$ $\mathrm{H}_{2} \mathrm{O}_{2}$ in potassium PBS (KPBS) for $30 \mathrm{~min}$ at room temperature (RT). Sections were washed twice ( $20 \mathrm{~min}, \mathrm{KPBS}$, at RT), followed by an overnight incubation in rabbit polyclonal antibody against EGFP $\left(4^{\circ} \mathrm{C}\right.$, Ab290, 1:10,000; Abcam, Cambridge, UK), 2\% normal goat serum, and $0.5 \%$ Triton X-100 in KPBS. Sections were then washed twice and incubated with goat anti-rabbit biotinylated antibody (1:200; Vector Laboratories, Burlingame, CA) in KPBS and 0.5\% Triton X-100. Sections were washed twice, incubated in an avidin-biotin-peroxidase complex ABC (1:100; Vector Laboratories) for $1 \mathrm{hr}$ at RT, followed by two washes, and then developed for $30 \mathrm{sec}$ using Vector SG substrate (Vector Laboratories). Sections were mounted in gelatin-coated glass slides, air dried, and dehydrated successively in 70, 96, and 100\% ethanol, followed by xylene. Slides were finally mounted with Permount (Fisher Scientific, Pittsburgh, PA) for bright-field microscopy.

Electrophysiology. Transverse hippocampal slices were prepared from P13-P225 POMC-EGFP mice and incubated in a solution containing the following (in mM): $125 \mathrm{NaCl}, 25 \mathrm{NaHCO}_{3}, 2.5 \mathrm{KCl}, 1.25 \mathrm{NaH}_{2} \mathrm{PO}_{4}, 0.5$ $\mathrm{CaCl}_{2}, 2.5 \mathrm{MgCl}_{2}$, and 25 D-glucose (bubbled with $95 \% \mathrm{O}_{2}-5 \% \mathrm{CO}_{2}$ ). The same extracellular solution was used for whole-cell recordings, except that $\mathrm{CaCl}_{2}$ was increased to $2.0 \mathrm{~mm}$ and $\mathrm{MgCl}_{2}$ was reduced to 1.0 $\mathrm{mm}$. Patch pipettes were filled with the following (in $\mathrm{mm}$ ): 140 K-gluconate or KCl, 10 EGTA, 10 HEPES, 2 Mg $_{2}$ ATP, 0.5 NaGTP, 20 phosphocreatine, and $0.2 \%$ biocytin, pH 7.3 (310 mOsm, 5-8 M $\Omega$ resistance). Currents were filtered at $2 \mathrm{kHz}$ and sampled at $10 \mathrm{kHz}$. Resting membrane potentials were measured immediately after patch rupture; junction potentials were not corrected. Action potential amplitudes were measured from threshold. Membrane time constants $\left(\tau_{\mathrm{m}}\right)$ were determined by fitting a single-exponential function to membrane responses to small hyperpolarizing current injections. The measured $R_{\text {input }}$ of newly born granule cells is likely an underestimate because $R_{\text {input }} \geq R_{\text {seal }}$. Data are expressed as mean \pm SEM.

Bromodeoxyuridine labeling. Adult POMC-EGFP transgenic mice (age 10-12 weeks) were given four bromodeoxyuridine (BrdU) injections (300 mg/kg in 0.9\% saline, i.p.; Sigma, St. Louis, MO) $2 \mathrm{hr}$ apart. At days $1,3,11,12$, and 30 after injection, the brains were fixed as described above. Horizontal sections through the ventral hippocampus $(100 \mu \mathrm{m})$ were cut on a vibratome and stored at $-20^{\circ} \mathrm{C}$ in cryoprotecting buffer (30\% ethylene glycol, 20\% glycerin, and $0.05 \mathrm{M}$ PBS). BrdU immunohistochemistry was performed simultaneously on sections from all intervals. Series of every sixth section through each hippocampus were processed. Free-floating sections were washed twice in KPBS, incubated in $2 \mathrm{~N} \mathrm{HCl}\left(30 \mathrm{~min}\right.$ at $\left.37^{\circ} \mathrm{C}\right)$, and rinsed in $0.1 \mathrm{M}$ borate buffer, $\mathrm{pH} 8.4$ (10 $\mathrm{min})$. Sections were incubated in KPBS-0.4\% Triton X-100-5\% normal goat serum for $30 \mathrm{~min}$, followed by overnight incubation with primary anti-BrdU antibody (monoclonal rat, 1:200; ImmunologicalsDirect.com, Oxfordshire, UK). After rinsing, sections were incubated for $1 \mathrm{hr}$ in Texas Red-conjugated goat anti-rat IgG (1:200; Jackson ImmunoResearch, Westgrove, PA). Sections were then incubated for $1 \mathrm{hr}$ in Alexa Fluor 488 rabbit anti-GFP IgG (1:500; Molecular Probes, Eugene, OR). Antibodies against GFAP (1:500; Sigma), neuronal-specific nuclear protein (NeuN) (1:1000; Chemicon, Temecula, CA), polysialylated form of neural cell adhesion molecule (PSA-nCAM) (1:400; Chemicon), parvalbumin (1:2000; Sigma), Tuc-4 (1:500; Chemicon), and $\beta$ III tubulin (TuJ1, 1:500; Chemicon) were used with standard protocols. Secondary antibodies were used against the appropriate species (1:200, goat antimouse IgM Alexa 555, donkey anti-mouse IgG Cy3, goat anti-rabbit Alexa 647; Molecular Probes). Sections were mounted with Prolong Antifade (Molecular Probes) and visualized with fluorescent or confocal microscopes. All cell counts were performed blind to the experimental condition. We counted the number of BrdU-positive nuclei positioned within or immediately adjacent to the granule cell layer $(>50$ cells per animal), the number of EGFP-positive cells ( $>400$ cells per animal), and the number of cells that colocalized BrdU and EGFP. For exercise experiments, mice were housed in rat cages with running wheels. Control liter mates were housed under identical conditions without running wheels. The number of EGFP-positive cells and the length of the subgranular zone were determined in two sections from the mid septo-temporal region of each mouse. Statistical significance was determined by $\chi^{2}$ tests or unpaired $t$ tests at the $p<0.05$ level.

\section{Results}

\section{Mouse POMC genomic regulatory sequences target reporter} genes to the dentate gyrus

Coincident with the detection of cell-specific EGFP expression in the two brain regions in which the POMC gene is known to be transcribed (the arcuate nucleus and the nucleus of tractus solitarius), we observed fluorescence in cells located in the subgranular region of the dentate gyrus of the hippocampus. EGFP fluorescence was clearly detected in presumed neuronal cell bodies restricted to the borders of the granule cell layer and, with lower signal intensity, in their projection neurites. We used a polyclonal anti-EGFP antibody to increase the sensitivity for EGFP detection in axons projecting to the stratum lucidum of CA3 and short dendrites extending to the inner molecular layer (Fig. 1) (supplemental Fig. 1, available at www.jneurosci.org). EGFP expression was not observed in other regions of the hippocampus. In the olfactory system, adult neurogenesis occurs in the subventricular zone and progeny migrate to the olfactory bulb. We also observed EGFP expression in the subventricular zone but not the olfactory bulb (data not shown).

In contrast to the arcuate nucleus, we were unable to detect POMC immunoreactivity in the dentate gyrus using polyclonal 

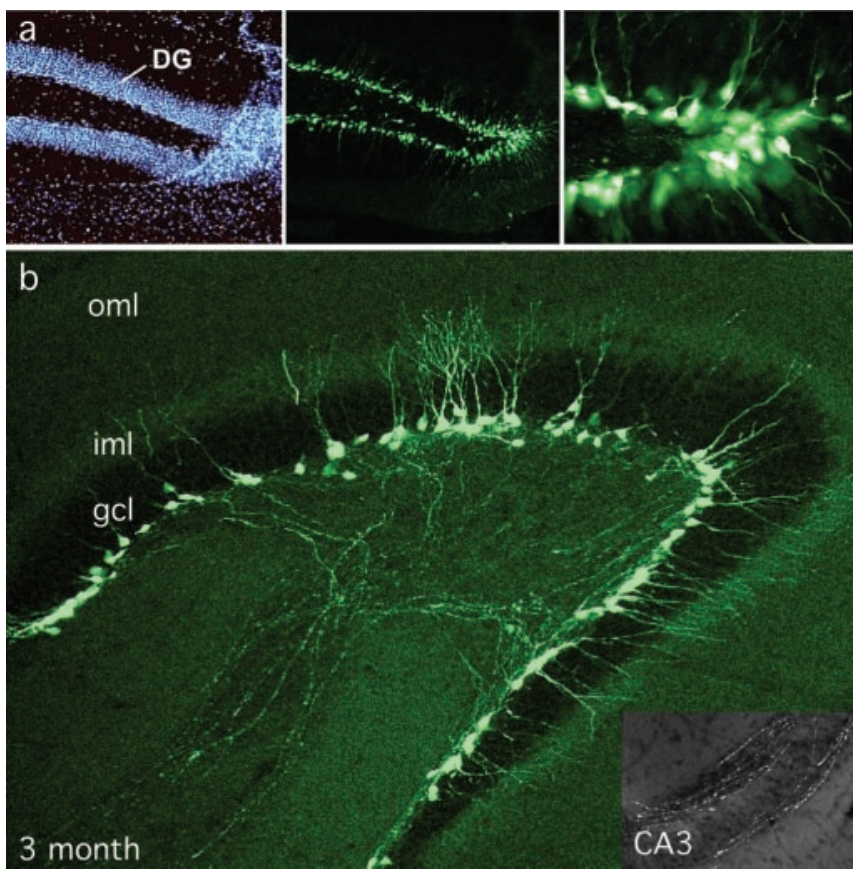

Figure 1. EGFP expression in the dentate gyrus of $-13 /+8$ POMC-EGFP transgenic mice. $a$, A coronal section stained with Hoechst 33258 (left) was also imaged with a FITC filter to detect EGFP green fluorescence (middle). A higher-power detail of the tip of the dentate gyrus (DG) is shown (right). b, A horizontal section from a 3-month-old POMC-EGFP mouse showing EGFPlabeled cell bodies at the inner border of the granule cell layer ( $\mathrm{gcl}$ ) with dendrites that project to the inner molecular layer (iml) but not the outer molecular layer (oml). Putative labeled mossy fibers project through the hilus to $C A 3$, with varicosities in stratum lucidum (inset). sequences showed expression in the dentate gyrus, as detected by an antisense oligonucleotide probe that recognized a heterologous 30-mer inserted in exon 3 (Fig. 2f) (Rubinstein et al., 1993). This correlation suggested that the mouse POMC 5' flanking region carries sequences that target gene expression to the dentate gyrus. We therefore analyzed several independent transgenic mouse lines that we produced to study brain-specific regulatory elements of the POMC gene (Fig. 2). A series of deletion and truncation constructs of the $13 \mathrm{~kb}$ promoter revealed that all fragments carrying $5^{\prime}$ flanking sequences from -0.8 to $-2 \mathrm{~kb}$ targeted transgenic expression to the subgranular layer (Fig. $2 a, b, f)$. In contrast, all transgenic mouse lines that lacked this 1.2 $\mathrm{kb}$ region showed no expression in the dentate gyrus (Fig. $2 c-e$ ). Interestingly, this fragment is dispensable for targeting authentic transgenic expression to POMC-expressing cells of the pituitary or the arcuate nucleus. The necessary sequences to target reporter genes to pituitary melanotrophs and corticotrophs reside downstream of the $-0.8 \mathrm{~kb}$ landmark (Liu et al., 1992; Rubinstein et al., 1993), and those responsible for authentic expression in POMCpositive cells in the arcuate nucleus reside upstream of the $-2 \mathrm{~kb}$ (Young et al., 1998).

\section{Immature excitable properties of dentate gyrus EGFP-positive cells}

To determine the functional properties of EGFP-positive cells, we made whole-cell recordings in acute hippocampal slices and compared their electrophysiological properties with neighboring unlabeled granule cells. Biocytin was included in the recording pipette for subsequent morphological analysis. The small cell bodies of biocytin-labeled EGFP-positive cells were located in the

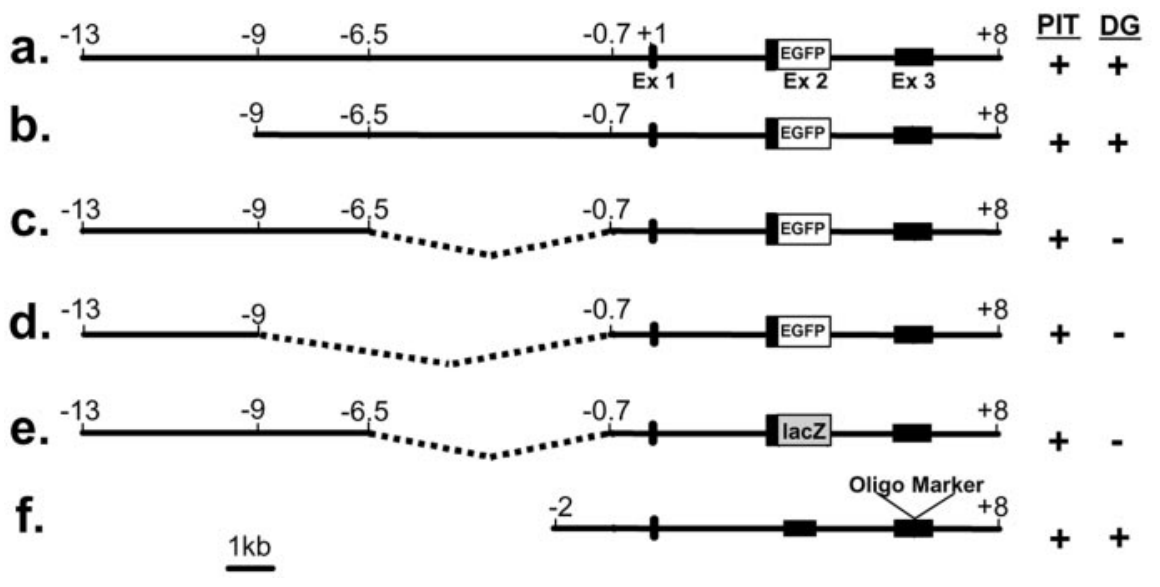

Figure 2. EGFP expression in the pituitary and dentate gyrus requires different promoter sequences. Transgene $a$ has EGFP coding sequences followed by a polyadenylation signal inserted in exon (Ex) 2 of the entire mouse POMC gene flanked by $13 \mathrm{~kb}$ of $5^{\prime}$ and $2 \mathrm{~kb}$ of $3^{\prime}$ sequences, respectively. Transgenes $b-d$ derive from transgene $a$ and contain different deletions of the mouse POMC promoter. Transgene e contains the same deletion as transgene $d$, but the reporter gene is Escherichia coli $\beta$-galactosidase. Transgene $f$ is a $10 \mathrm{~kb}$ genomic mouse POMC fragment carrying a foreign 30 -mer sequence inserted in exon 3 . Authentic transgenic expression in melanotrophs and corticotrophs of the pituitary gland (PT) is indicated by a + sign. Transgenic expression in the dentate gyrus (DG) is indicated on the right column with a + sign and absence of expression with a - sign. The three POMC exons are indicated with black boxes.

antibodies raised against different POMC-derived peptides, even in colchicine-treated mice. In situ hybridization performed with a mouse exon 3 riboprobe also failed to detect POMC mRNA in the dentate gyrus from early postnatal, 3-week-old, and adult transgenic and nontransgenic mice. Previously, we observed that two of six transgenic mouse lines carrying the transcriptional unit of the mouse POMC gene together with $2 \mathrm{~kb}$ of $5^{\prime}$ and $3^{\prime}$ flanking inner granule cell layer, and their presumed axons traversed the hilus and terminated in stratum lucidum of CA3. In contrast to mature granule cells, however, EGFP-positive cells had multiple neurites arising from the cell bodies and short, spineless dendrites that terminated in the inner molecular layer (Fig. $3 a-c$ ). This morphology suggested that EGFP-positive cells were immature granule cells.

Compared with unlabeled granule cells, EGFP-positive granule cells had slower membrane time constants $\left(\tau_{\mathrm{m}}=106 \pm 16\right.$ msec, $n=8$ vs $\left.\tau_{\mathrm{m}}=30 \pm 4 \mathrm{msec}, n=6\right)$, higher input resistance $(8.4 \pm 2.0$ vs $550 \pm$ $182 \mathrm{M} \Omega$ ), and more depolarized resting membrane potentials $(-47 \pm 4$ vs $-77 \pm$ $1 \mathrm{mV})$. Step depolarization from a holding potential of $-70 \mathrm{mV}$ elicited fast inward currents that were blocked by tetrodotoxin $(n=3)$. These voltage-dependent $\mathrm{Na}^{+}$ currents were significantly smaller in EGFP-positive cells ( $228 \pm 50 \mathrm{pA} ; n=12)$ compared with unlabeled granule cells $(7166 \pm 1429$ pA; $n=5)$ (Fig. $3 d, e)$ but had similar kinetics. In current-clamp recordings, current injection from a holding potential of $-70 \mathrm{mV}$ triggered single action potentials in eight of eight EGFP-positive cells. However, compared with mature granule cells $(n=6)$, action potentials in EGFP-positive cells had smaller peak amplitudes (35 \pm 5 vs $88 \pm 5 \mathrm{mV}$, measured from threshold) and prolonged durations (half-width, $9.3 \pm 2.4$ vs $1.3 \pm 0.2 \mathrm{msec}$ ) (Fig. $3 d, e$ ). Consistent with the lack of EGFP-positive dendrites in 

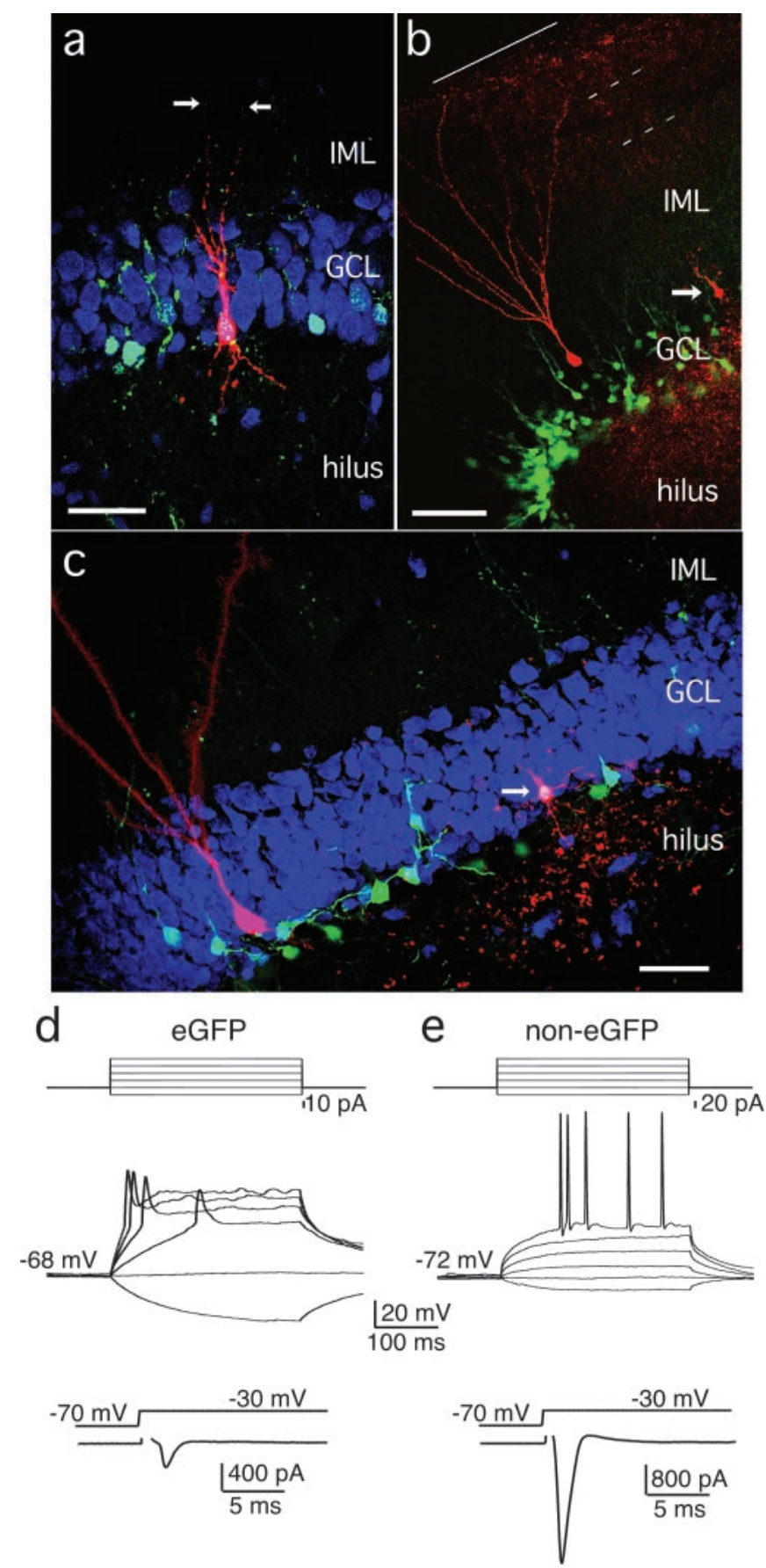

Figure 3. EGFP-positive granule cells have immature morphology and excitability. a, A confocal stack through a typical EGFP-positive cell filled with biocytin (red) from a P18 mouse. The dendrites terminated in the inner molecular layer (IML, arrows), and multiple neurites arose from the cell body. Other EGFPexpressing cell bodies (green) were present in the granule cell layer (GCL), colocalized with propidium iodide nuclear stain (blue). Scale bar, $20 \mu \mathrm{m} . b$, Biocytin-filled cells show the dendritic structure of a mature nonEGFP granule cell and EGFP-positive granule cells in a slice from a 3-month-old mouse. The dendrites of a typical mature granule cell (left) extended through all layers of the molecular layer. Dotted lines indicate the approximate locations of the lateral and medial perforant paths. In contrast, the dendrites of a biocytin-filled EGFP-positive cell (arrow) terminated within the inner molecular layer. Scale bar, $40 \mu \mathrm{m}$. c, The confocal image of the cells in $b$ shows the position of EGFP-positive cell bodies (green) along the border of the granule cell layer and hilus. The filled EGFP-positive cell (arrow) was triple labeled for biocytin, EGFP, and propidium iodide.Scalebar, $20 \mu \mathrm{m}$.d,Top, Currentinjections intoEGFP-positivecells elicited small action potentials with slow kinetics. Only single action potentials were observed. Bottom, Voltage steps from a holding potential of -70 to $-30 \mathrm{mV}$ generated small TIX-sensitive $\mathrm{Na}^{+}$currents. e, Top, In contrast to EGFP-positive cells, unlabeled granule cells responded to currentinjections with multiplelarge and fastaction potentials. Bottom, Voltage steps to $-30 \mathrm{mV}$ generated $\mathrm{Na}^{+}$currents that were, on average, 10-fold larger than currents in EGFP-positive cells. the middle and outer molecular layer, stimulation of the perforant path did not evoke excitatory synaptic currents in labeled cells $(-70 \mathrm{mV})$, although robust AMPA receptor-mediated EPSCs were generated in unlabeled granule cells under the same conditions (data not shown). However, stimulation within the granule cell layer evoked small GABAergic IPSCs (134 $\pm 26 \mathrm{pA}$ at $-70 \mathrm{mV} ; n=5$; data not shown) in EGFP-labeled cells. Similar results were obtained in recordings from adult animals $(>3$ months) and 3-week-old mice. Altogether, these characteristics are similar to those reported for immature granule cells from postnatal tissue (Liu et al., 1996, 2000). Depolarized resting membrane potentials and small, broad action potentials are also characteristic of immature neurons in other brain regions (Huguenard et al., 1988; Picken Bahrey and Moody, 2003).

\section{EGFP-positive cells are $\sim \mathbf{2}$ weeks postmitotic}

To directly assess the age of EGFP-positive cells, we administered BrdU to adult age-matched transgenic mice that subsequently were perfused at intervals between 1 and $30 \mathrm{~d}$ after injection. We chose an injection paradigm that labels a large fraction of S-phase cells without toxicity (Cameron and McKay, 2001; Hayes and Nowakowski, 2002). None of the BrdU-positive cells were colabeled with EGFP $1 \mathrm{~d}$ after the BrdU injection $(n=2 ;>250$ BrdU-positive cells counted) (Fig. 4a). However, $3 \mathrm{~d}$ after the BrdU injection, a small percentage of the BrdU-labeled cells were also EGFP positive $(4.7 \pm 1.2 \% ; n=5)$ (Fig. $4 b)$. By $11 \mathrm{~d}$, there was a high degree of colocalization, with $60 \pm 5 \%$ of BrdUpositive cells also expressing EGFP $(n=3)$. At $30 \mathrm{~d}$, the percentage of colocalization dropped to $1.5 \pm 1 \%(n=3 ; p<0.01)$. In a separate set of injections, $73 \pm 6 \%$ of BrdU-positive cells also expressed EGFP at a 12 d interval $(n=3)$. We never observed colocalization of BrdU and EGFP in POMC-expressing neurons in the arcuate nucleus. In the dentate gyrus, there was no difference in the average number of EGFP-positive cells across time intervals (range, 59-75 cells per section). There was a significant reduction in the number of BrdU-positive cells between the 3, 11, and $30 \mathrm{~d}$ intervals $(27.7 \pm 3.5,8.4 \pm 0.8$, and $5.6 \pm 0.9$ cells per section, respectively). This reduction is consistent with the death of newly born cells that occurs during the first weeks after adult neurogenesis in the subgranular layer (Hayes and Nowakowski, 2002; Dayer et al., 2003). Although the number of BrdU-positive cells was significantly reduced at the $11 \mathrm{~d}$ interval, colocalization with EGFP increased, indicating that EGFP expression labels newborn granule cells that survive the initial period of cell death. The high colocalization between BrdU and EGFP suggests that most, if not all, adult-generated granule cells are transiently labeled.

\section{EGFP-positive cells express immature neuronal markers}

All of the results presented thus far support the idea that EGFPpositive cells are newborn granule cells. However, we also considered the possibility that some EGFP-labeled cells could be parvalbumin-expressing interneurons (Liu et al., 2003) or newly born glial cells (Fukuda et al., 2003). Immunolabeling for parvalbumin (Fig. 5a, red) confirmed that there was no colocalization between EGFP and the large basket cell body and dense plexus of parvalbumin-positive axon terminals in the granule cell layer. The size of the cell body and axonal projection pattern clearly differentiated basket cells from EGFP-positive cells. The lower input resistance and fast-spiking behavior of basket cells also distinguished the two cell types (Fig. 5a, left). Furthermore, there was no coexpression of EGFP and the glial protein GFAP (Fig. $5 c$ ). There was, however, close apposition between GFAP- 


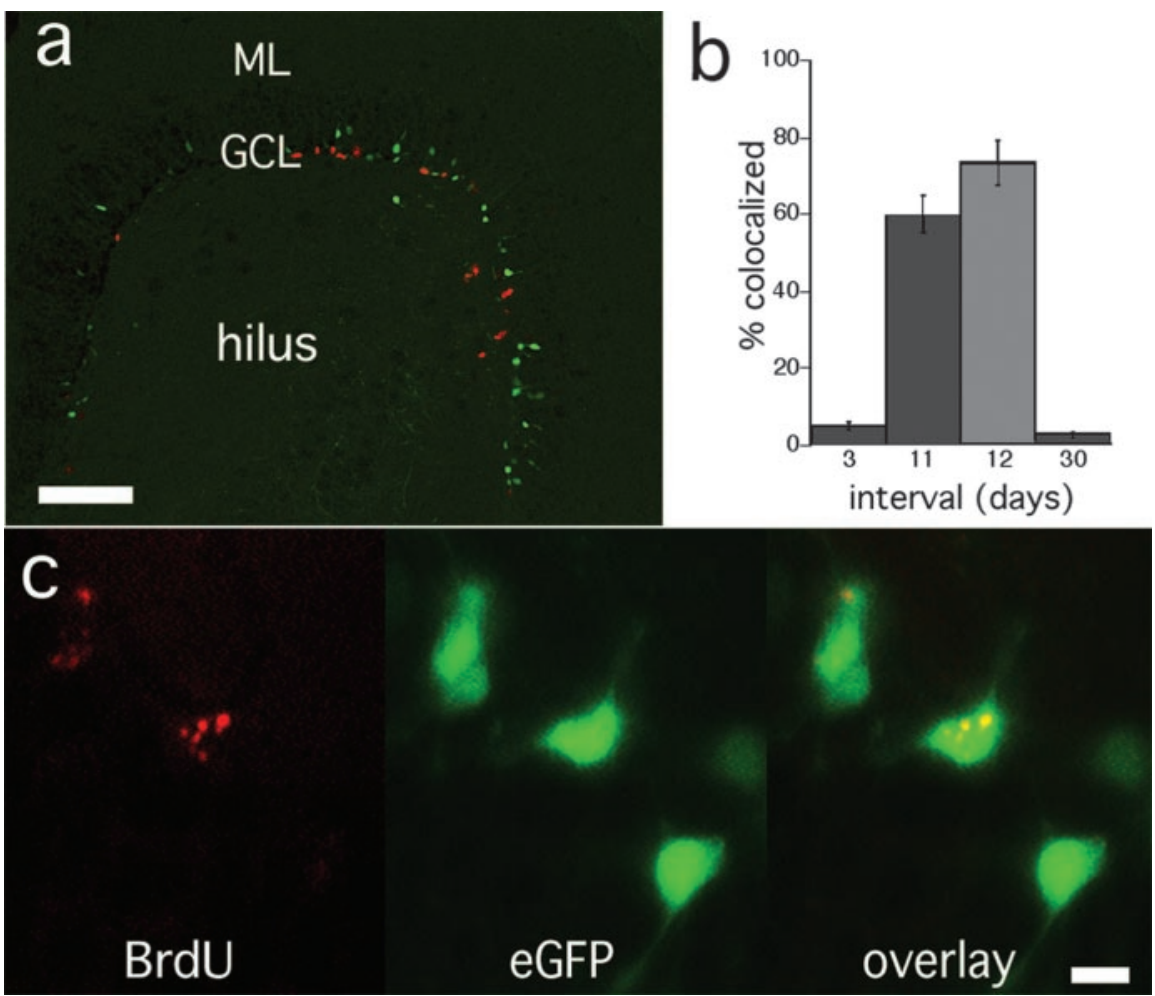

Figure 4. EGFP-expressing granule cells are $\sim 2$ weeks postmitotic. $a$, Low-magnification image of BrdU-labeled nuclei (red) and EGFP-expressing cells (green) in the dentate gyrus at $1 \mathrm{~d}$ after BrdU injection. Scale bar, $100 \mu \mathrm{m}$. No colabeling was seen at this short interval. $b$, The percentage of BrdU-positive cells that were colocalized with EGFP depended on the interval after BrdU injection. A small fraction of BrdU-labeled cells were also EGFP positive at $3 \mathrm{~d}$ ( 43 BrdU positive and EGFP positive of 852 BrdU positive; $n=5$ mice). A high degree of colocalization was observed 11 and $12 \mathrm{~d}$ after BrdU injection (110 of 183 and 439 of 583 , respectively; $n=3$ each), and this was reduced at $30 \mathrm{~d}$ ( 4 of 183; $p<0.01 ; n=3$ ). c, High-magnification single confocal image showing colocalization of EGFP and BrdU. Scale bar, $6 \mu \mathrm{m}$. GCL, Granule cell layer; ML, molecular layer.

expressing fibers and EGFP-positive cells. In contrast, EGFPpositive cells expressed PSA-nCAM (Fig. 5b), an extracellular glycoprotein expressed by immature granule cells (Seki and Arai, 1993; Seki and Arai, 1999). Of 150 randomly selected EGFPpositive cells, 145 were colabeled with PSA-nCAM (97\%; $n=3$ animals). Cells expressing low levels of EGFP appeared to have the strongest PSA-nCAM labeling; there were PSA-nCAMpositive cells with larger cell bodies that did not express EGFP. Thus, EGFP expression seems to overlap with the early stages of PSA-nCAM expression. Consistent with this timing, many EGFP-labeled cells also expressed the immature neuronal markers TuJ1 and Tuc-4 (Cameron and McKay, 2001; Seki, 2002) but were only weakly positive or immunonegative for the mature marker NeuN (supplemental Fig. 2).

\section{The number of EGFP-labeled granule cells parallels neurogenesis}

We expected that modulation of adult neurogenesis should alter the number of EGFP-labeled granule cells. Because granule cell proliferation declines with age (Kuhn et al., 1996), we first compared EGFP expression in immature, young adult, and aged mice. The number and density of EGFP-expressing cells in the dentate gyrus declined dramatically with age (Fig. $6, a, b, d, e, g, h$ ), in contrast to EGFP-POMC-positive neurons of the arcuate nucleus, which remained unaltered throughout adulthood (Fig. 6f,i). At P8, there was a high density of labeled cells packed together in close proximity (Fig. $6 a-c$ ). The number of EGFP-positive cells was more limited in young adult mice (Fig. $6 d, e$ ). Sixteen-month- old mice showed only a few EGFP-positive cells spread along the subgranular zone (Fig. $6 g, h$ ). The localization of cells expressing EGFP in the hippocampus was restricted to the granule cell layer, except in postnatal tissue where migrating granule cells in stratum oriens were also labeled (supplemental Fig. 1).

We also expected that enhanced neurogenesis stimulated by exercise (van Praag et al., 1999a,b) would increase the number of EGFP-expressing granule cells. To test this, we provided mice with running wheels and counted the number of labeled cells after 2 and 4 weeks of voluntary exercise. After 4 weeks of running, the number of EGFP-positive cells increased by $46 \%$ compared with controls $(7.3 \pm 0.9$ cells/ $100 \mu \mathrm{m}$ after running, $n=6$ vs $5.0 \pm 0.3$ cells/100 $\mu \mathrm{m}$ in control, $n=5$ ). This corresponds to an increase in the average number of cells per section from $67 \pm 5$ cells in control $(n=5)$ to $101 \pm 13$ after running $(n=6 ; p<0.05)$ (Fig. 7$)$. There was not a significant change in the number of labeled cells after 2 weeks of wheel running $(10.1 \pm 1.1$ cells $/ 100 \mu \mathrm{m}$ after running, $n=5$ vs $8.4 \pm 0.4$ cells $/ 100 \mu \mathrm{m}$ in control, $n=3 ; p=0.13)$. The difference in labeled cells between control mice reflects the different ages of the mice; mice were 4 months old at the end of the 4 week study and 2.5 months old at the end of the 2 week study. Although 2 weeks of running is sufficient to increase granule cell proliferation (van Praag et al., 1999b), it was not sufficient to detect enhanced EGFP expression. This is consistent with the idea that EGFP-positive cells are $\sim 2$ weeks postmitotic. These results indicate that EGFP-expressing granule cells will be useful for detecting changes in neurogenesis.

\section{Discussion}

Specificity and selectivity of the marker for newborn granule cells

Mouse POMC genomic regulatory sequences demonstrated authentic tissue-specific properties by targeting EGFP expression to POMC neurons of the arcuate nucleus and the nucleus of the solitary tract, as well as pituitary melanotrophs and corticotrophs. However, these genomic sequences also induced high levels of reporter expression in the dentate gyrus, a region in which POMC gene expression has never been described. Our failure to detect POMC immunoreactivity or POMC mRNA in the mouse hippocampus is consistent with all known POMC gene brain expression studies and therefore indicates that hippocampal EGFP expression is ectopic. However, this ectopic expression is not attributable to chromosomal influences in the vicinity of transgene integration because it was present in independent transgenic pedigrees carrying EGFP, as well as other reporter genes (Rubinstein et al., 1993). Moreover, transgenic mice carrying a large mouse genomic fragment contained in a bacterial artificial chromosome (BAC) engineered to express EGFP from the POMC gene also show expression in the subgranular region of the dentate gyrus (Gong et al., 2003). The 
consistent, although ectopic, expression of transgenes requires cryptic sequences localized between -2 and $-0.8 \mathrm{~kb}$ of the $5^{\prime}$ flanking region upstream of the mouse POMC promoter. Interestingly, this necessary region for dentate expression of reporter genes is dispensable for appropriate expression of transgenes in POMC cells of the hypothalamus, the brainstem, or the pituitary. Given that this region consistently directs the expression of transgenes to the dentate gyrus, it may be useful to target newborn neurons with other genes, such as Cre recombinase to induce loxPmediated cell-specific mutations or the diphtheria toxin gene to induce specific cell ablation. The reason the endogenous POMC gene is not expressed in newly born granule cells could be attributable to the existence of cis-acting transcriptional silencers absent in the transgenes used here and in the BAC used in the GENSAT project (Gene Expression Nervous System Atlas, funded by the National Institute of Neurological Disorders and Stroke). Alternatively, the endogenous POMC locus may acquire a unique chromosomal conformation that silences gene expression that is not maintained at a foreign chromosomal integration site.

Transient expression of EGFP in immature granule cells suggests that transgenes may be transcriptionally activated by factors expressed during a brief window of granule cell development. The lack of widespread expression in early postnatal brain suggests that it is not a ubiquitous marker for all immature neurons. However, the high percentage of colocalization between EGFP and BrdU in the dentate suggests that most, if not all, granule cells transiently express EGFP. Members of the group IV POUdomain subfamily of transcription factors have been implicated in neuronal differentiation, process outgrowth, and expression of synaptic proteins (Smith et al., 1997) and have been shown to interact with elements present in the POMC promoter (Gerrero et al., 1993). NeuroD1, a basic helix-loop-helix transcription factor essential for differentiation of granule cells (Miyata et al., 1999; Schwab et al., 2000), is also implicated in cell-specific transcription of POMC gene expression (Poulin et al., 2000). Additional studies will be required to determine the identity of the cis-acting elements and transcription factors that participate in the developmentally regulated expression of reporter genes driven by $5^{\prime}$ flanking sequences of the mouse POMC gene.

Our studies complement other new techniques that allow visualization of adult-generated neurons. Recently, the long-term fate of adult-generated cells in the hippocampus was studied in vivo (van Praag, 2002) and in vitro (Song et al., 2002a,b) using EGFP-expressing retroviral vectors. Adult-generated granule cells in the olfactory bulb have been studied in a similar manner (Belluzzi et al., 2003; Carleton et al., 2003). This method allows newborn cells to be permanently labeled, but has the disadvantage of low and variable expression levels requiring intracerebral injections of the virus, and can also label proliferating glia. Transgenic mice expressing POMC-EGFP have the advantage of reliably labeling an entire population of neurons at a particular developmental stage. This property facilitates the study of newborn granule cells at different ages of the mouse. Upregulation and downregulation of EGFP-labeled cells after exercise and aging, respectively, also suggests that this marker is suitable for detecting alterations in neurogenesis.

Our results indicate that EGFP expression was restricted to neurons rather than astrocytes or glia. First, EGFP-labeled axons projected to CA3, a characteristic of mossy fibers. Second, EGFPpositive cells expressed the immature markers PSA-nCAM, TuJ1, and Tuc- 4 but did not express GFAP. Finally, EGFP-positive cells had excitable membrane properties consistent with a neuronal rather than glial phenotype. The general uniformity of membrane properties, morphology, and expression patterns suggested that EGFP expression was restricted to a relatively homogenous population of immature neurons. Recently, the nestin promoter has been used to drive expression of EGFP in progenitor cells of the dentate gyrus and subventricular zone (Yamaguchi et al., 2000; Filippov et al., 2003). In contrast to our results, however, nestin-EGFP expression in the dentate gyrus revealed two sub- 

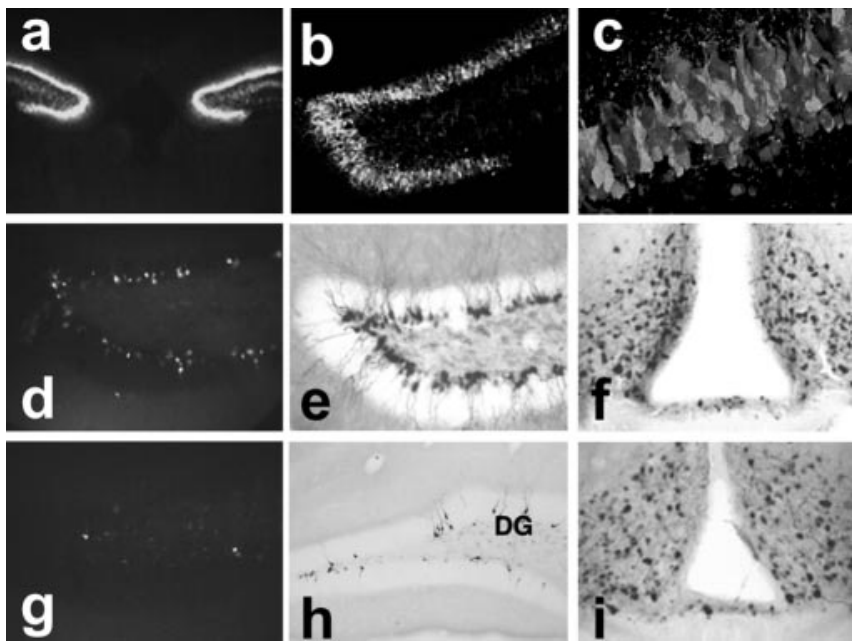

Figure 6. The number of EGFP-positive cells in the dentate gyrus (DG) declines with age. Coronal sections from $-13 /+8$ POMC-EGFP transgenic mice obtained at P8 $(a-c), 3$ months $(d-f)$, and 16 months $(g, h)$. EGFP expression was maximal at P8 and clearly detectable at low magnification $(a)$. Confocal resolution $(b, c)$ showed a high density of cells. EGFP-positive cells in the hippocampus were fewer at 3 months $(d, e)$ and 16 months $(g, h)$. In contrast, the number of EGFP-positive neurons in the arcuate nucleus was similar at 3 and 16 months $(f, i)$. EGFP was detected by green fluorescence $(a-d, g)$ or immunohistochemistry $(e, f$ and $h, i)$.
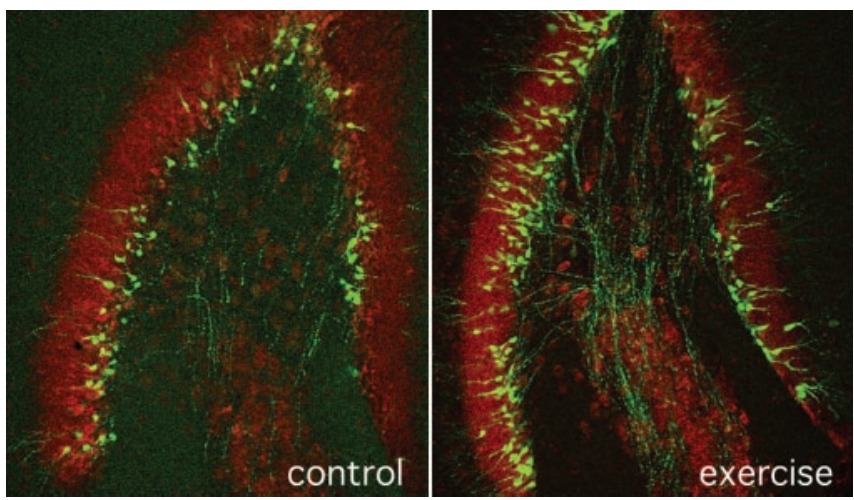

Figure 7. Exercise increases the number of EGFP-labeled granule cells. Mice housed with running wheels for 4 weeks had more EGFP-labeled cells (right) compared with control liter mates (left). Images are flattened confocal stacks (10 slices per $1.4 \mu \mathrm{m}$ ) through horizontal sections of the dentate gyrus $(20 \times)$. Exercise increased the number of cells per $100 \mu \mathrm{m}$ of dentate, as well as the number of cells per section. The cell body layers were labeled with propidium iodide (red).

populations of cells exhibiting distinct glial and early neuronal phenotypes (Fukuda et al., 2003). BrdU labeling suggested that the nestin-positive cells progressed from glial-like properties to early neuronal properties within days of division. The morphology, excitable properties, and BrdU labeling of the EGFP-positive neurons reported here indicate that they are more highly differentiated, i.e., "older," than the previously reported nestin-EGFPlabeled cells. Thus, POMC-EGFP expression may indicate the first stage at which newborn granule cells can be considered neurons.

\section{Fate of newborn neurons}

The slow membrane time constant, high input resistance, and small action potentials of EGFP-positive granule cells are typical features of neurons in immature preparations. These immature characteristics were present in labeled cells from adult as well as juvenile mice, indicating that they are a function of the develop- mental stage of the cell rather than the age of the animal. The properties of these immature granule cells are consistent with the sequence of maturation that occurs during prenatal development of CA1 pyramidal cells (Tyzio et al., 1999), in which voltagedependent $\mathrm{Na}^{+}$currents and spike generation precedes the formation of functional GABAergic and finally glutamatergic synapses. However, this sequence would appear to differ from the development of adult-generated granule cells of the olfactory bulb. Here, migrating granule cells receive functional GABAergic and glutamatergic synapses before the ability to generate action potentials (Carleton et al., 2003) (but see Belluzzi et al., 2003). The acquisition of action potential generation may be related to axonal development, because newly born dentate granule cells have well developed axons within 1 week after final cell division (Hastings and Gould, 1999; Jones et al., 2003; these results), whereas olfactory bulb granule cells do not have axons.

During the first month after cell division, many newborn cells die (Dayer et al., 2003). In mice, one-half of BrdU-labeled cells die within $8 \mathrm{~d}$ (Hayes and Nowakowski, 2002). Many of these cells may be immature neurons (Cameron and McKay, 2001), although there is a similar reduction of BrdU-positive cells expressing either vascular or glial markers (Palmer et al., 2000). We detected a reduction in the number of BrdU-positive cells between 3 and $11 \mathrm{~d}$ after BrdU injection yet simultaneously found a dramatic increase in colocalization between BrdU and EGFP. Thus, EGFP-expressing neurons survive the initial period of cell death. Although our current results do not indicate the long-term fate of these immature granule cells, the decline in colabeling at $30 \mathrm{~d}$ cannot be attributable to death of the entire population because we only detected a modest reduction in BrdU-labeled cells between 11 and $30 \mathrm{~d}$. This scenario would also result in more cell death than observed previously (Hayes and Nowakowski, 2002; Dayer et al., 2003). Rather, the decline in BrdU and EGFP colocalization indicates that EGFP expression is transient and terminates within $30 \mathrm{~d}$. EGFP-labeled cells sent axons to CA3, displayed action potentials, and evoked inhibitory synaptic currents, indicating that they were partially integrated into the existing network. This partial integration may promote survival, although this idea has not been tested.

\section{Extrinsic factors may delay the development of adult-generated neurons}

Some adult-generated granule cells can fully integrate into the dentate circuitry by 1 month after division (van Praag et al., 2002). Similarly, stem cells develop properties of fully functional neurons under appropriate culture conditions (Song et al., 2002a,b). However, little is known about the molecular and temporal cues underlying this process. Although it might be predicted that granule cell maturation proceeds in a continuous manner, the rather homogenous characteristics of EGFP-labeled cells suggests that development proceeds by way of several discrete steps. It is expected that these discrete steps reflect patterns of gene expression. Following this idea, essentially all EGFPlabeled neurons expressed PSA-nCAM, and many expressed Tuj1 and Tuc-4. Furthermore, EGFP-labeled neurons either weakly expressed, or did not express, the mature neuronal marker NeuN. Stepwise changes in gene expression may be regulated by intrinsic or extrinsic factors. Our observation that EGFP expression in the subventricular zone turns off before migrating cells reach the olfactory bulb suggests that the temporal pattern of EGFP expression in the olfactory system differs from the dentate gyrus (Winner et al., 2002). This suggests that local extrinsic signaling is influential. Additional preliminary results suggest that the tem- 
poral window of EGFP expression in the dentate also depends on the age of the animal and other environmental influences. Our results indicate that 2 weeks after final division, adult-generated granule cells have immature excitability and short, spine-free dendrites that do not project past the inner molecular layer. This contrasts with the time course of granule cell maturation during embryonic development, in which the "oldest" granule cells have relatively mature morphology and physiology by the end of the first postnatal week (Liu et al., 2000; Jones et al., 2003). Granule cell neurogenesis occurs late during the embryonic period (Angevine, 1965; Schlessinger et al., 1975); therefore, these early generated cells are similar in age to the EGFP-positive cells in adult tissue. Thus, the time course of maturation must be slower for adult-generated granule cells compared with those produced during the embryonic and early postnatal period. It is likely that extrinsic factors in adult tissue may be less favorable compared with early development, thereby retarding and/or preventing the maturation, as well as proliferation (Kuhn et al., 1996; Dayer et al., 2003) of newborn neurons.

\section{References}

Angevine Jr JB (1965) Time of neuron origin in the hippocampal region: an autoradiographic study in the mouse. Exp Neurol [Suppl] 2:1-70.

Belluzzi O, Benedusi M, Ackman J, LoTurco JJ (2003) Electrophysiological differentiation of new neurons in the olfactory bulb. J Neurosci 23:10411-10418.

Biebl M, Cooper CM, Winkler J, Kuhn HG (2000) Analysis of neurogenesis and programmed cell death reveals a self-renewing capacity in the adult rat brain. Neurosci Lett 291:17-20.

Cameron HA, McKay RD (2001) Adult neurogenesis produces a large pool of new granule cells in the dentate gyrus. J Comp Neurol 435:406-417.

Carleton A, Petreanu LT, Lansford R, Alvarez-Buylla A, Lledo PM (2003) Becoming a new neuron in the adult olfactory bulb. Nat Neurosci 6:507-518.

Cowley MA, Smart JL, Rubinstein M, Cerdan MG, Diano S, Horvath TL, Cone RD, Low MJ (2001) Leptin activates anorexigenic POMC neurons through a neural network in the arcuate nucleus. Nature 411:480-484.

Dayer AG, Ford AA, Cleaver KM, Yassaee M, Cameron HA (2003) Shortterm and long-term survival of new neurons in the rat dentate gyrus. J Comp Neurol 460:563-572.

Filippov V, Kronenberg G, Pivneva T, Reuter K, Steiner B, Wang LP, Yamaguchi M, Kettenmann H, Kempermann G (2003) Subpopulation of nestin-expressing progenitor cells in the adult murine hippocampus shows electrophysiological and morphological characteristics of astrocytes. Mol Cell Neurosci 23:373-382.

Fukuda S, Kato F, Tozuka Y, Yamaguchi M, Miyamoto Y, Hisatsune T (2003) Two distinct subpopulations of nestin-positive cells in adult mouse dentate gyrus. J Neurosci 23:9357-9366.

Gerrero MR, McEvilly RJ, Turner E, Lin CR, O'Connell S, Jenne KJ, Hobbs MV, Rosenfeld MG (1993) Brn-3.0: a POU-domain protein expressed in the sensory, immune, and endocrine systems that functions on elements distinct from known octamer motifs. Proc Natl Acad Sci USA 90:10841-10845.

Gong S, Zheng C, Doughty ML, Losos K, Didkovsky N, Schambra UB, Nowak NJ, Joyner A, Leblanc G, Hatten ME, Heintz N (2003) A gene expression atlas of the central nervous system based on bacterial artificial chromosomes. Nature 425:917-925.

Hastings NB, Gould E (1999) Rapid extension of axons into the CA3 region by adult-generated granule cells. J Comp Neurol 413:146-154.

Hayes NL, Nowakowski RS (2002) Dynamics of cell proliferation in the adult dentate gyrus of two inbred strains of mice. Brain Res Dev Brain Res 134:77-85.

Huguenard JR, Hamill OP, Prince DA (1988) Developmental changes in $\mathrm{Na}^{+}$conductances in rat neocortical neurons: appearance of a slowly inactivating component. J Neurophysiol 59:778-795.

Jones SP, Rahimi O, O’Boyle MP, Diaz DL, Claiborne BJ (2003) Maturation of granule cell dendrites after mossy fiber arrival in hippocampal field CA3. Hippocampus 13:413-427.

Kaplan MS, Hinds JW (1977) Neurogenesis in the adult rat: electron microscopic analysis of light radioautographs. Science 197:1092-1094.
Kuhn HG, Dickinson-Anson H, Gage FH (1996) Neurogenesis in the dentate gyrus of the adult rat: age-related decrease of neuronal progenitor proliferation. J Neurosci 16:2027-2033.

Liu B, Hammer GD, Rubinstein M, Mortrud M, Low MJ (1992) Identification of DNA elements cooperatively activating proopiomelanocortin gene expression in the pituitary glands of transgenic mice. Mol Cell Biol 12:3978-3990.

Liu J, Solway K, Messing RO, Sharp FR (1998) Increased neurogenesis in the dentate gyrus after transient global ischemia in gerbils. J Neurosci $18: 7768-7778$

Liu S, Wang J, Zhu D, Fu Y, Lukowiak K, Lu Y (2003) Generation of functional inhibitory neurons in the adult rat hippocampus. J Neurosci 23:732-736.

Liu X, Tilwallis S, Ye G, Lio PA, Pasternak JF, Trommer BL (2000) Morphologic and electrophysiologic maturation in developing dentate granule cells. Brain Res 856:202-212.

Liu YB, Lio PA, Pasternak JF, Trommer BL (1996) Developmental changes in membrane properties and postsynaptic currents of granule cells in rat dentate gyrus. J Neurophysiol 76:1074-1088.

Lois C, Alvarez-Buylla A (1994) Long-distance neuronal migration in the adult mammalian brain. Science 264:1145-1148.

Magavi SS, Leavitt BR, Macklis JD (2000) Induction of neurogenesis in the neocortex of adult mice. Nature 405:951-955.

McEwen BS (1999) Stress and hippocampal plasticity. Annu Rev Neurosci 22:105-122.

Miyata T, Maeda T, Lee JE (1999) NeuroD is required for differentiation of the granule cells in the cerebellum and hippocampus. Genes Dev 13:1647-1652.

Nottebohm F (2002) Neuronal replacement in adult brain. Brain Res Bull 57:737-749.

Palmer TD, Willhoite AR, Gage FH (2000) Vascular niche for adult hippocampal neurogenesis. J Comp Neurol 425:479-494.

Picken Bahrey HL, Moody WJ (2003) Early development of voltage-gated ion currents and firing properties in neurons of the mouse cerebral cortex. J Neurophysiol 89:1761-1773.

Poulin G, Lebel M, Chamberland M, Paradis FW, Drouin J (2000) Specific protein-protein interaction between basic helix-loop-helix transcription factors and homeoproteins of the Pitx family. Mol Cell Biol 20:4826-4837.

Rochefort C, Gheusi G, Vincent JD, Lledo PM (2002) Enriched odor exposure increases the number of newborn neurons in the adult olfactory bulb and improves odor memory. J Neurosci 22:2679-2689.

Rubinstein M, Mortrud M, Liu B, Low MJ (1993) Rat and mouse proopiomelanocortin gene sequences target tissue-specific expression to the pituitary gland but not to the hypothalamus of transgenic mice. Neuroendocrinology 58:373-380.

Santarelli L, Saxe M, Gross C, Surget A, Battaglia F, Dulawa S, Weisstaub N, Lee J, Duman R, Arancio O, Belzung C, Hen R (2003) Requirement of hippocampal neurogenesis for the behavioral effects of antidepressants Science 301:805-809.

Schlessinger AR, Cowan WM, Gottlieb DI (1975) An autoradiographic study of the time of origin and the pattern of granule cell migration in the dentate gyrus of the rat. Comp Neurol 159:149-175.

Schwab MH, Bartholomae A, Heimrich B, Feldmeyer D, Druffel-Augustin S, Goebbels S, Naya FJ, Zhao S, Frotscher M, Tsai MJ, Nave KA (2000) Neuronal basic helix-loop-helix proteins (NEX and BETA2/Neuro D) regulate terminal granule cell differentiation in the hippocampus. J Neurosci 20:3714-3724.

Seki T (2002) Expression patterns of immature neuronal markers PSANCAM, CRMP-4 and NeuroD in the hippocampus of young adult and aged rodents. J Neurosci Res 70:327-334.

Seki T, Arai Y (1993) Highly polysialylated neural cell adhesion molecule (NCAM-H) is expressed by newly generated granule cells in the dentate gyrus of the adult rat. J Neurosci 13:2351-2358.

Seki T, Arai Y (1999) Temporal and spatial relationships between PSANCAM-expressing, newly generated granule cells, and radial glia-like cells in the adult dentate gyrus. J Comp Neurol 410:503-513.

Smith MD, Dawson SJ, Latchman DS (1997) The Brn-3a transcription factor induces neuronal process outgrowth and the coordinate expression of genes encoding synaptic proteins. Mol Cell Biol 17:345-354.

Snyder JS, Kee N, Wojtowicz JM (2001) Effects of adult neurogenesis on synaptic plasticity in the rat dentate gyrus. J Neurophysiol 85:2423-2431. 
Song H, Stevens CF, Gage FH (2002a) Astroglia induce neurogenesis from adult neural stem cells. Nature 417:39-44.

Song HJ, Stevens CF, Gage FH (2002b) Neural stem cells from adult hippocampus develop essential properties of functional CNS neurons. Nat Neurosci 5:392-394.

Tyzio R, Represa A, Jorquera I, Ben-Ari Y, Gozlan H, Aniksztejn L (1999) The establishment of GABAergic and glutamatergic synapses on CA1 pyramidal neurons is sequential and correlates with the development of the apical dendrite. J Neurosci 19:10372-10382.

van Praag H, Christie BR, Sejnowski TJ, Gage FH (1999a) Running enhances neurogenesis, learning, and long-term potentiation in mice. Proc Natl Acad Sci USA 96:13427-13431.

van Praag H, Kempermann G, Gage FH (1999b) Running increases cell proliferation and neurogenesis in the adult mouse dentate gyrus. Nat Neurosci 2:266-270.

van Praag H, Schinder AF, Christie BR, Toni N, Palmer TD, Gage FH (2002)
Functional neurogenesis in the adult hippocampus. Nature 415:1030-1034.

Wang S, Scott BW, Wojtowicz JM (2000) Heterogenous properties of dentate granule neurons in the adult rat. J Neurobiol 42:248-257.

Winner B, Cooper-Kuhn CM, Aigner R, Winkler J, Kuhn HG (2002) Longterm survival and cell death of newly generated neurons in the adult rat olfactory bulb. Eur J Neurosci 16:1681-1689.

Yamaguchi M, Saito H, Suzuki M, Mori K (2000) Visualization of neurogenesis in the central nervous system using nestin promoter-GFP transgenic mice. NeuroReport 11:1991-1996.

Young JI, Otero V, Cerdan MG, Falzone TL, Chan EC, Low MJ, Rubinstein M (1998) Cell-specific and developmentally regulated expression of proopiomelanocortin genomic fragments in hypothalamic and hindbrain neurons of transgenic mice. J Neurosci 18:6631-6640.

Zhang LI, Poo MM (2001) Electrical activity and development of neural circuits. Nat Neurosci [Suppl] 4:1207-1214. 